\title{
ISSN:
}

Print - $2277-0755$

Online - $2315-7453$

(C) FUNAAB 2020

\author{
Journal of \\ Agricultural \\ Science
}

FUNAAB 2020

and Environment

\section{A PRELIMINARY COMPARISON OF MITOCHONDRIAL D-LOOP REGION OF FUNAAB ALPHA AND NIGERIAN INDIGENOUS CHICKENS}

\author{
${ }^{*}$ 'S.O. DUROSARO, ${ }^{1 B}$ B.T. OSHINOWO, ${ }^{1}$ A.C. AKPOJO, ${ }^{1}$ L.T. OLUYOMBO, \\ ${ }^{2}$ I.C. NWOSU, , ${ }^{3}$ O.S. IYASERE, ${ }^{1 B}$.M. ILORI, , ${ }^{4}$ E.V. IKPEME, AND \\ 1OZOJE, M.O. \\ ${ }^{1}$ Department of Animal Breeding and Genetics, Federal University of Agriculture, \\ Abeokuta, Nigeria \\ 2Department of Animal/Fisheries Science and Management, Enugu State University of \\ Science and Technology, Agbani, Enugu State, Nigeria \\ 3Department of Animal Physiology, Federal University of Agriculture, Abeokuta, Nigeria \\ ${ }^{4}$ Department of Genetics and Biotechnology, University of Calabar, Calabar, Cross River \\ State, Nigeria \\ *Corresponding Author:durosaroso@funaab.edu.ng, Tel: +2347069464530
}

\begin{abstract}
Nigerian indigenous chickens possess immunity from endemic diseases and have a better survival rate than commercial hybrid strains under local production conditions. FUNAAB Alpha chicken was developed by improving Nigerian indigenous chickens through crossbreeding and selection. This study compared the mitochondrial d-loop of FUNAAB Alpha and Nigerian indigenous chickens to check likely genetic erosion and loss of diversity in development of FUNAAB Alpha breed. Blood samples were collected from Nigerian indigenous $(n=23)$ and FUNAAB Alpha $(n=20)$ chickens sampled from farms and houses in Ogun state, Nigeria. The Hypervariable 1 (HV1) of the mitochondrial d-loop region was amplified and sequenced. Single nucleotide polymorphisms present in HV1 of chickens were identified using Clustal W. Genetic diversity of the region was determined using DnaSp v5 while selective forces acting on the chickens were predicted using HyPhy software implemented inside MEGA 6 software. Phylogenetic relationship among FUNAAB Alpha, Nigerian indigenous and other chicken breeds was determined using MEGA 6 software. Five polymorphisms were identified in FUNAAB Alpha chickens while twelve were identified in Nigerian indigenous chickens. All the polymorphisms identified in FUNAAB Alpha chickens were also observed in Nigerian indigenous chickens while seven polymorphisms were unique to Nigerian indigenous chickens. Higher diversity indices were observed in Nigerian indigenous chickens (number of haplotype: 4; haplotype diversity: $0.743 \pm 0.012$; nucleotide diversity: $0.014 \pm 0.0013$ and average number of nucleotide differences: 4.332 ) compared with FUNAAB Alpha chickens (number of haplotype: 2; haplotype diversity: $0.485 \pm 0.001$; nucleotide diversity: $0.008 \pm 0.0001$ and average number of nucleotide differences: 2.424). Positive selective forces were acting on FUNAAB Alpha chickens while negative selective forces were acting on Nigerian indigenous chickens. Phylogenetic analysis revealed that FUNAAB Alpha chickens clustered with Nigerian indigenous and South American chickens. It can be concluded that there was likely genetic erosion and loss of diversity in development of FUNAAB Alpha breed. Breeding programmes aimed at improvement of genetic diversity and reduction of genetic erosion should be applied in subsequent improvement of FUNAAB Alpha chickens.
\end{abstract}

Keywords: chickens, diversity, genetic erosion, phylogeny, polymorphism, selection 


\section{INTRODUCTION}

Nigerian indigenous chicken is a dual purpose bird raised for meat and egg production in the rural and peri-urban communities in Nigeria (Sonaiya and Olori, 1990). These indigenous chickens play major roles in Nigerian rural economies and contribute significantly to Gross National Product of Nigeria (Momoh et al., 2007; Omondi, 2018). They have a better meat flavour and are self-reliant with the capacity to withstand harsh weather condition. The birds possess the ability to hatch their own eggs, brood and scavenge for major parts of their feeds. Their products are preferred by many Nigerians because of the pigmentation, taste, leanness and suitability for special dishes (Horst, 1989). They also possess immunity from endemic diseases and have a better survival rate than commercial hybrid strains under local production conditions (Minga et al., 2004).

FUNAAB Alpha chicken, which was developed by improving Nigerian indigenous chickens, was officially registered as a new breed in 2018. The selection process for the traits of economic importance (meat and egg) in this chicken breed started in 1997 with over 10 generations of selections for improved meat and egg production. There are two types of FUNAAB Alpha chickens: the meat line and the dual purpose line. The feather colour of the meat line is usually white. The average body weight at hatch of meat line FUNAAB Alpha chickens ranges from $35-42 \mathrm{~g}$ while average body weight at 8 weeks varies between $1.2-1.5 \mathrm{~kg}$. The dual purpose FUNAAB Alpha chickens are phenotypically the same in term of feather colours with Nigerian indigenous chickens. The average chick weight at hatch is between 30-35 g while body weight at maturity can reach $1600 \mathrm{~g}$ (Ilori et al., 2017).
Population genetics studies focus on finding genetic variations in mitochondrial DNA because mutations in this region are higher than other genomic regions (Mannen et al., 2004). Animal mitochondrial DNA follows maternal inheritance strictly and is highly variable within a species, making it important for genetic diversity analysis and phylogenetic inference (Wolf et al., 1999). Also, analysis of the mitochondrial DNA can be used for tracing the origins of animals as well as identifying individual animals (Anderson $e t$ al., 1981; Teinlek et al., 2018).

The present study compared the genetic diversity between FUNAAB Alpha and Nigerian indigenous chickens in order to check the likely genetic erosion and loss of diversity involved in the development of FUNAAB Alpha chickens. The type of selection force acting on the two chicken breeds was also predicted. The relatedness of the two chicken breeds with other chicken breeds was also determined.

\section{MATERIALS AND METHODS Sampling location and experimental ani- mals}

Twenty-three (23) Nigerian indigenous and 20 FUNAAB Alpha chickens were sampled from various farms and households in Ogun State Nigeria. Each bird was sampled from farms and houses separated by $10 \mathrm{~km}$ to avoid sampling of birds that are closely related. The birds were sampled from Ilaro, Ota, Ijebu-Igbo, Ifo, Odeda, Sagamu, Ipokia and Ijebu-Ode. Ogun State has a landmass of $16,980 \mathrm{Km}^{2}$, altitude of $66 \mathrm{~m}$ above sea level, temperature range of $21-34^{\circ} \mathrm{C}$, relative humidity of $85 \%$ and located on $7^{\circ} 00^{\prime} \mathrm{N} 3^{\circ}$ $35^{\prime} \mathrm{E}$ coordinates. The capital of the state is Abeokuta and the major river in the State is Ogun River. 
A PRELIMINARY COMPARISON OF MITOCHONDRIAL D-LOOP REGION...

Blood collection

About $1 \mathrm{ml}$ of blood was collected from brachial vein of each chicken using needle and syringe. Individual blood sample was deposited in heparinised bottle.

\section{DNA extraction}

Genomic DNA (gDNA) was extracted from the blood of the birds at Biotechnol- ogy Laboratory of the Department of Animal Breeding and Genetics, Federal University of Agriculture, Abeokuta from the chickens using Zymo research quick-gDNATM miniprep kit (catalogue number: D3024)

Amplification and sequencing of mitochondrial d-loop region

Amplification was carried out using

L16750_Fwd 5'-AGGACTACGGCTTGAAAAGC-3' (Akishinonomiya et al., 1996) and H547_Rev 5'-ATGTGCCTGACCGAGGAACCAG-3' (Liu et al., 2006)

primers to amplify 600 bp region covering the whole of Hypervariable 1 (HV1) region and other parts of chicken mitochondrial dloop. For amplification, $5 \mu \mathrm{l}$ of genomic DNA ( $10-20 \mathrm{ng})$ was added to a reaction mixture containing $12.8 \mu \mathrm{l}$ of nuclease free water, $2.5 \mu \mathrm{l}$ of $1 \times$ PCR buffer, $1.5 \mu$ of $1.5 \mathrm{mM} \mathrm{MgCl}, 1 \mu \mathrm{l}$ of $0.2 \mathrm{mM}$ dNTP, $1 \mu \mathrm{l}$ of $0.4 \mathrm{UM}$ forward primer, $1 \mu \mathrm{l}$ of $0.4 \mathrm{UM}$ reverse primer and $0.2 \mu \mathrm{l}$ of $2 \mathrm{U} / \mu \mathrm{l}$ surf Hot Taq. The PCR conditions included initial denaturation at $96^{\circ} \mathrm{C}$ for 15 minutes, 35 cycles of final denaturation at $95^{\circ} \mathrm{C}$ for 30 seconds, annealing at $56^{\circ} \mathrm{C}$ for 30 seconds, extension at $70^{\circ} \mathrm{C}$ for 1 minute and final extension at $70^{\circ} \mathrm{C}$ for 5 minutes. The amplicon was purified with Magnetic Beads Carboxylate (MCLab, USA). Sequencing of amplicon was done with BigDye Terminator v. 3.1 using the instrument $3730 \mathrm{XL}$ following the supplier's protocol at STAB Vida Genetics Laboratory, Campus FCT UNL Edificio Departmental de Quimica, Laboratorio 009, 2829-516 Caparica, Portugal.

\section{Analysis of mitochondrial d-loop se- quences}

The Hypervariable 1 (HV1) sequences (546 $\mathrm{bp}$ ) of mitochondrial d-loop region of FUNAAB Alpha and Nigerian indigenous chickens were trimmed and edited using
Bioedit (Hall, 1999) and MEGA v6 (Tamura et al., 2013). The single nucleotide polymorphisms (SNPs) present in the HV1 region were identified by alignment with reference d -loop sequence (AB829490) using Clustal W (Thompson et al., 1994).

Genetic diversity indices such as singleton variable site, parsimony informative site, number of haplotype, haplotype diversity, average number of nucleotide differences and nucleotide diversity were estimated using DnaSp v5 (Librado and Rozas, 2009).

Tajima's D; Fu and Li's D*; and Fu's Fs tests were performed to test the mitochondrial dloop HV1 region of the chickens for deviation from neutrality using DnaSP v5 (Librado and Rozas, 2009).

Mean synonymous substitution per synonymous site (dS) and mean non-synonymous substitution per non-synonymous site (dN) were estimated for the region to predict the type of selection acting on the birds using HyPhy software implemented inside MEGA v6 software (Tamura et al., 2013). Positive $\mathrm{dN}$-dS suggested positive selection while negative $\mathrm{dN}-\mathrm{dS}$ suggested negative selection. MEGA v6 software (Tamura et al., 2013) was used to determine the phylogenetic relation- 
ship among FUNAAB Alpha, Nigerian indigenous and other chicken breeds. The phylogenetic tree was inferred using neighbor joining method. The reliability of the inferred tree was evaluated using bootstrap analysis of 1000 replications.

\section{RESULTS}

Polymorphisms identified in mitochondrial d-loop $H V 1$ region of FUNAAB Alpha and Nigerian indigenous chickens

The polymorphisms identified in the mito- chondrial d-loop HV1 region of FUNAAB Alpha and Nigerian indigenous chickens are shown in Table 1 . Five polymorphisms were identified in FUNAAB Alpha chickens while twelve were identified in Nigerian indigenous chickens. All the polymorphisms identified in FUNAAB Alpha chickens were also observed in Nigerian indigenous chickens while seven polymorphisms were unique to Nigerian indigenous chickens.

Table 1: Polymorphisms identified in mitochondrial d-loop HV1 region of FUNAAB Alpha and Nigerian indigenous chickens

\begin{tabular}{lll}
\hline Breed & $*$ Polymorphism & Reference allele \\
\hline FUNAAB Alpha & $222 \mathrm{~A}>\mathrm{G}$ & $\mathrm{G}$ \\
$249 \mathrm{~A}>\mathrm{G}$ & $\mathrm{G}$ \\
$281 \mathrm{~A}>\mathrm{G}$ & $\mathrm{A}$ \\
$342 \mathrm{~A}>\mathrm{G}$ & $\mathrm{A}$ \\
$355 \mathrm{~T}>\mathrm{C}$ & $\mathrm{C}$ \\
& & \\
Nigerian indigenous & $222 \mathrm{~A}>\mathrm{G}$ & $\mathrm{G}$ \\
& $225 \mathrm{C}>\mathrm{T}$ & $\mathrm{C}$ \\
& $243 \mathrm{C}>\mathrm{T}$ & $\mathrm{C}$ \\
& $249 \mathrm{~A}>\mathrm{G}$ & $\mathrm{G}$ \\
$256 \mathrm{C}>\mathrm{T}$ & $\mathrm{C}$ \\
$261 \mathrm{~T}>\mathrm{C}$ & $\mathrm{T}$ \\
$281 \mathrm{~A}>\mathrm{G}$ & $\mathrm{A}$ \\
$310 \mathrm{C}>\mathrm{T}$ & $\mathrm{T}$ \\
$342 \mathrm{~A}>\mathrm{G}$ & $\mathrm{A}$ \\
$355 \mathrm{~T}>\mathrm{C}$ & $\mathrm{C}$ \\
$358 \mathrm{~A}>\mathrm{G}$ & $\mathrm{A}$ \\
$446 \mathrm{~T}>\mathrm{C}$ & $\mathrm{T}$ \\
\hline
\end{tabular}

*The polymorphisms were named based on complete mitochondrial d-loop sequence of chicken 
A PRELIMINARY COMPARISON OF MITOCHONDRIAL D-LOOP REGION...

Genetic diversity of FUNAAB Alpha presented in Table 2. Higher diversity indices and Nigerian indigenous chickens were observed in Nigerian indigenous chickGenetic diversity indices of FUNAAB Al- ens compared with FUNAAB Alpha chickpha and Nigerian indigenous chickens are ens.

Table 2: Genetic diversity indices of FUNAAB Alpha and Nigerian indigenous chickens

\begin{tabular}{lll}
\hline Diversity indices & FUNAAB Alpha & Nigerian indigenous \\
\hline Number of sequences analysed & 20 & 23 \\
Singleton variable site & 0 & 0 \\
Parsimony informative site & 5 & 12 \\
Number of haplotype & 2 & 4 \\
Haplotype diversity & $0.485 \pm 0.001$ & $0.743 \pm 0.012$ \\
Nucleotide diversity & $0.008 \pm 0.0001$ & $0.014 \pm 0.0013$ \\
Average number of nucleotide differences & 2.424 & 4.332 \\
\hline
\end{tabular}

Deviation of mitochondrial d-loop $\boldsymbol{H V 1}$ rian indigenous chickens from neutrality is region of FUNAAB Alpha and Nigerian shown in Table 3. All the test of deviation indigenous chickens from neutrality from neutrality indices estimated for the two Test of deviation of mitochondrial d-loop chicken breeds were positive and greater HV1 region of FUNAAB Alpha and Nige- than 1.

Table 3: Test of deviation of mitochondrial d-loop HV1 region of FUNAAB Alpha and Nigerian indigenous chickens from neutrality

\begin{tabular}{lll}
\hline Deviation from neutrality test & FUNAAB Alpha & Nigerian indigenous \\
\hline Tajima's D & 1.71 & 1.15 \\
Fu and Li's D & 1.26 & 1.46 \\
Fu's Fs & 5.04 & 5.32 \\
\hline
\end{tabular}

Type of selection acting on FUNAAB Alpha and Nigerian indigenous chickens

The likely selective forces acting on FUNAAB Alpha and Nigerian indigenous chickens are as presented in Table 4. Positive selective forces were acting on FUNAAB Alpha chickens while Negative Selective forces were acting on Nigerian indigenous chickens. 
Table 4: Selective forces acting on FUNAAB Alpha and Nigerian indigenous chickens

\begin{tabular}{lllll}
\hline Breed & dN & dS & dN-dS & Type of selection \\
\hline FUNAAB Alpha & 1.80 & 1.27 & 0.53 & Positive selection \\
Nigerian indigenous & 3.44 & 5.70 & -2.26 & Negative selection \\
\hline
\end{tabular}

Phylogenetic relationship among 1 . The phylogenetic analysis revealed that the FUNAAB Alpha, Nigerian indigenous FUNAAB Alpha chickens, South American and other chicken breeds and Nigerian indigenous chickens clustered The phylogenetic relationship among FU- together. All the Asian chickens clustered $\mathrm{NAAB}$ Alpha, Nigerian indigenous and together with the Indian red jungle chicken other chicken breeds is presented in Figure forming their ancestor.

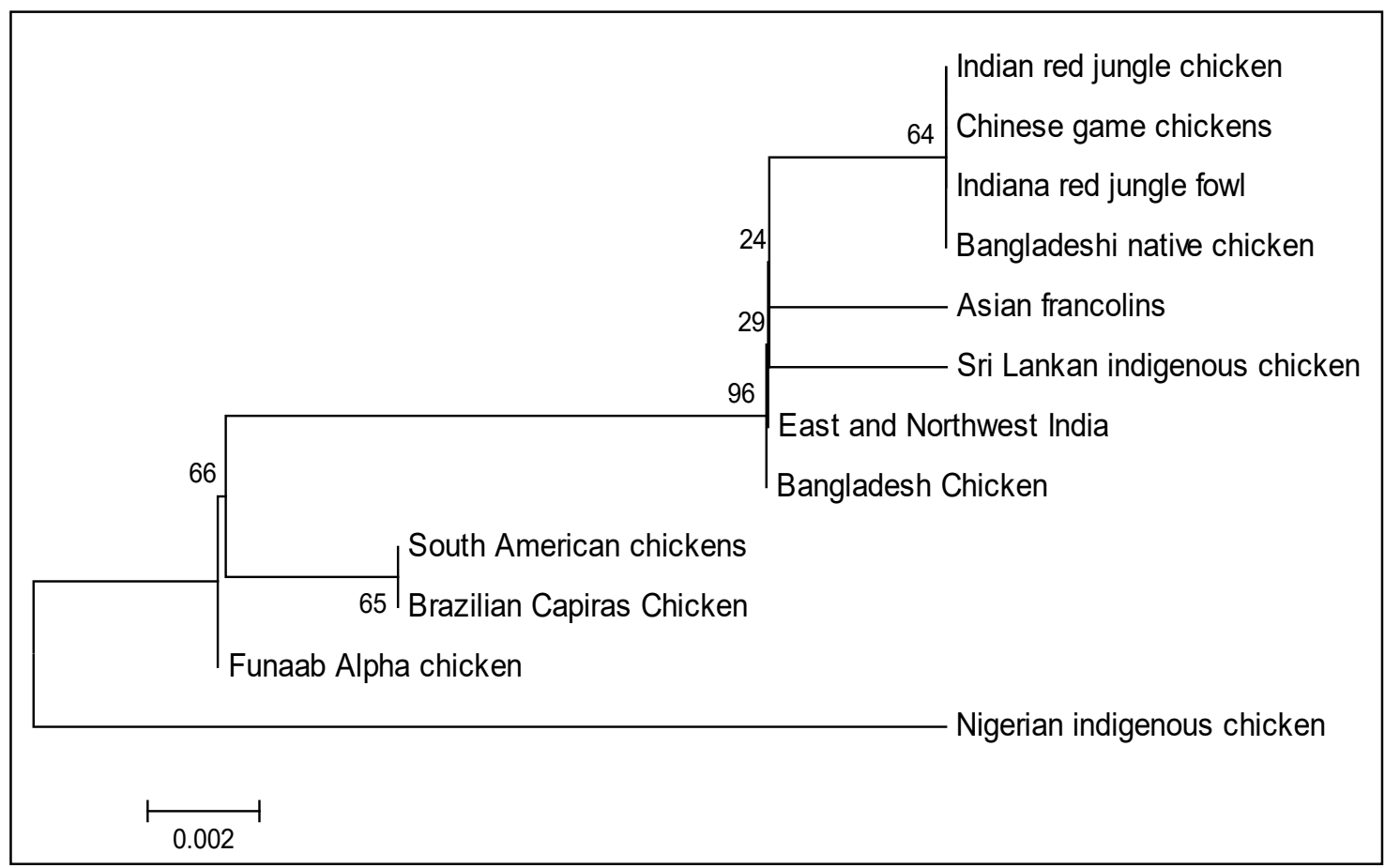

Figure 1: Phylogenetic relationship among FUNAAB Alpha, Nigerian indigenous and other chicken breeds 
A PRELIMINARY COMPARISON OF MITOCHONDRIAL D-LOOP REGION...

\section{DISCUSSION}

Comparison of mitochondrial d-loop HV1 region of FUNAAB Alpha and Nigerian indigenous chickens presented the molecular genetics evidences of likely genetic erosion and loss of diversity in development of FUNAAB Alpha chickens.

The alignment of the HV1 region of the mitochondrial d-loop region of the two breeds revealed high variability at regions 222 to $446 \mathrm{bp}$. Regions from 167 to $397 \mathrm{bp}$ were found to have higher variation in Sudanese domestic chickens by Wani et al. (2014). The presence of more polymorphisms in Nigerian indigenous chickens compared with FUNAAB Alpha chickens was not surprising as the indigenous chickens used in this study were from rural farms and houses, with the birds not subjected to artificial selection like FUNAAB Alpha chickens. Some polymorphisms were present in Nigerian indigenous chickens but absent in FUNAAB Alpha chickens. Absence of some polymorphisms in FUNAAB Alpha chickens was an indication that some variations have been lost during development of FUNAAB Alpha chickens from Nigerian indigenous chickens.

Haplotype diversity range of 0.485 to 0.743 observed in our study was in the range of 0.39 to 0.88 reported for African chickens by Adebambo et al. (2010), Mtileni et al. (2011), Osman et al. (2016) and Ajibike et al. (2017). The lower haplotype and nucleotide diversity observed in FUNAAB Alpha chickens was an indication that the breed is less heterozygote and younger on the evolutionary time scale of domestic chickens. Ancient populations are more likely to be genetically more diverse compared to their derived or recent counterparts (Savolainen et al., 2002). Haplotype diversity is affected by breeding histories of chickens and selection (Joshi et al., 2013). Generally, the low genetic diversity observed in FUNAAB Alpha chickens was an indication of loss of genetic diversity in this breed. Livestock species are most times bred under strong selection that concentrates on few traits of economic importance with this type of breeding resulting in loss of genetic diversity (Taberlet et al., 2011). The genetic diversity is fundamental for sustainable genetic improvement, facilitating the rapid adaptation to necessary and unpredicted change to the development of production system (Mariante and Egito, 2002).

Positive tests of deviation from neutrality indices obtained for FUNAAB Alpha and Nigerian indigenous chickens was an indication of presence of both low and high frequency mutations which can be linked to positive selection and decrease in population size (Hahn et al., 2002). Since negative selection was observed in Nigerian indigenous chickens, positive selection can be excluded as the cause of these positive tests of deviation from neutrality indices and we can confidently assume decrease in population size to be the cause. The surprising result is the observation of positive tests of deviation from neutrality indices in FUNAAB Alpha chickens as positive tests of deviation from neutrality indices result from many haplotypes (Simmonsen et al., 1995) but only two haplotypes were found in the FUNAAB ALPHA breed of chicken used in our study.

Negative selection forces predicted in Nigerian indigenous chickens are likely used by the breed for selection against newly arising deleterious mutations for preservation of biological functions. Negative selection acts on all natural populations and it is mainly for genomic sequence conservation across evo- 
lutionary timescales (Elyashiv et al., 2016). Also, negative selection is the most prevalent form of selection as it constantly sweeps away deleterious mutations that are produced in each generation and keeps the animal fit. It is a natural selection through which alleles with reduced fitness or viability are lost in the population. Since most keepers of Nigerian indigenous chickens don't provide drugs, vaccines and sometimes feeds for their birds, this type of selection aids in survival and fitness of the birds. Another importance of negative selection is to ensure that new mutations are either lost or fixed rapidly within individuals and thus exposed to selection at the population level (Bergstrom and Pritchard, 1998).

Positive selection forces observed in FUNAAB Alpha chickens might be linked to fixation of alleles. Many alleles that are involved in adaptation, growth and egg production are being fixed in FUNAAB Alpha chickens as it is a new breed that needs to be productive and adapted to tropical climate of Nigeria. Positive selection forces are involved in fixation of alleles that are involved in fitness. Identification of regions that are subjected to positive selection can help answer whether genetic differences between population have adaptive significance (Andolfatto, 2005).

Phylogenetic analysis revealed that FUNAAB Alpha, South American and Nigerian Indigenous were closely related. Close relationship among these chicken breeds implied high comparability and evolution from a common ancestor. Clustering together of FUNAAB Alpha and Nigerian indigenous chickens was not surprising as FUNAAB Alpha chickens were developed from Nigerian indigenous chickens. Also there are two lines of FUNAAB Alpha chickens, the meat and dual purpose lines. The meat line was developed by crossing Nigerian indigenous chickens with exotic broilers while the dual purpose line was developed through selection of Nigerian indigenous chickens for many generations. The exotic breed used in the development of meat line could probably be from South America as FUNAAB Alpha chicken clustered with them on the phylogenetic tree. There was a duplication event in the evolution tree with all the Asian chickens clustering together and Indian red jungle chicken formed the ancestral lineage of all chickens. Formation of ancestral lineage by Indian red jungle chicken supported the hypothesis that domestic chickens originated from the tropical jungle fowl of the genus Gallus (Crawford, 1990).

\section{CONCLUSIONS}

There was likely genetic erosion and loss of diversity in development of FUNAAB Alpha breed. Positive selective forces are acting on FUNAAB Alpha chickens while Nigerian indigenous chicken is undergoing negative selection. Phylogenetic analysis revealed likely crossing of South American chickens with Nigerian indigenous chickens during the development of meat type FUNAAB Alpha chickens

\section{REFERENCES}

Adebambo, A.O., Mobegi, V.A., Mwacharo, J.M., Oladejo, B.M., Adewale, R.A, Ilori, L.O., Makanjuola, B.O., Afolayan, O., Bjornstad, G., Jianlin, H., Hanotte, O. 2010. Lack of phylogeographic structure in Nigerian village chickens revealed by mitochondria DNA D-loop sequence analysis. International Journal of Poultry Science 9: 503-507.

Ajibike, A.B., Adeleye, O.O., Ilori, B.M., Osinbowale, D.A., Adeniyi, O.A., Du- 
A PRELIMINARY COMPARISON OF MITOCHONDRIAL D-LOOP REGION...

rosaro, S.O., Sanda, A.J., Adebambo, O.A., Adebambo, A.O. 2017. Genetic diversity, phlogeographic structure and effect of selection at the mitochondrial Hypervariable region of Nigerian chicken populations. Journal of Genetics 96(2): 959-968.

Akishinonomiya, F., Miyake, T., Takada, M., Shingu, R., Endo, T., Gojobori, T., Kondo, N., Ohno, S. 1996. Monophyletic origin and uniques dispersal patterns of domestic fowls. Proceedings of the National Academy of Science of United States of America 93: 6792-6795.

Anderson, S., Bankier, A.T., Barell, B.G., Debruijn, M.H., Coulson, A.R., Drouin, J., Young, I.G. 1981. Sequence and organization of the human mitochondrial genome. Nature 290(5806): 457-467

Andolfatto, P. 2005. Adaptive evolution of non-coding DNA in Drosophila. Nature 437: 1149-1152.

Bergstrom, C.T., Pritchard, J. 1998. Germline bottlenecks and the evolutionary maintenance of mitochondrial genome. Genetics 149: 2135-2146.

Crawford, R.D. 1990. Poultry breeding and genetics. $1^{\text {st }}$ edition, Elsevier Science Publishers, Amsterdam. Pp 1-42.

Desjardins, P., Conklin, D. 2010. Nanodrop microvolume quantification of nucleic acid. Journal of Visualized Experiments 22(45): 2565.

Elyashiv, E., Sattath, S., Hu, T.T., Strutsovsky, A., McVicker, G. 2016. A genomic map of the effects of linked selection in drosophila. PLoS Genetics 12:e1006130.
Hahn, M.W., Rausher, M.D., Cunningham, C.W. 2002.Distinguishing between selection and population expansion in an experimental lineage of Bacteriophage T7. Genetics 161: 11-20.

Hall, T. A. 1999. BioEdit: A user-friendly biological sequence alignment editor and analysis program for windows 95/98/NT. Nucleic Acids Symposium Series 41: 95-98.

Horst, P. 1989. Native fowl as reservoir for genomes and major genes with direct and indirect effects on the adaptability and their potential for tropically oriented breeding plans. Archiv fur Geflugelkunde 53(3): 93-101.

Ilori, B.M., Oyeniyi-Dada, Q.A., Ayankeye, T.R., Hamzat, F., Durosaro, S.O., Wheto, M., Adebambo, A.O., Adebambo, O.A. 2017. Effect of crossbreeding and selection for meat on Nigerian indigenous chickens. Bulletin of Animal Health and Production in Africa 65: 277-287.

Joshi, J., Salar, R.K., Banerjee, P., Upasna, S., Tantia, M.S., Vijh, R.K. 2013. Genetic variation and phylogenetic relationships of Indian buffaloes of Uttar Pradesh. Asian Australian Journal of Animal Science 26(9): 1229-1236.

Librado, P., Rozas, J. 2009. DnaSP v5: A software for comprehensive analysis of DNA polymorphism data. Bioinformatics 25 (11): 1451-1452.

Liu, Y., Wu, G., Yao, Y., Miao, Y., Luikart, G., Baig, m., Beja-Pereira, A., Ding, Z., Palanichamy, M.G., Zhang, Y. 2006. Multiple maternal origin of chickens: Out of the Asian jungles. Molecular Phylogenetics and Evolution 38: 12-19. 
of Egyptian native chickens based on com-

Mannen, H., Kohno, M., Nagata, Y., Tsuji, S., Bradley, D.G., Yeo, J.S., Amanof, T. 2004. Independent mitochondrial origin historical genetic differentiation in North Eastern Asian cattle. Molecular Phylogenetics and Evolution 32(2): 539-544.

Marinate, A.S., Egito, A.A. 2002. Animal genetic resources in Brazil: Results of five centuries of natural selection. Theriogenology 57(1): 223-235.

Minga, U.M., Msoffe, P.L., Gwasika, P.S. 2004. Biodiversity (variation) in disease resistance and in pathogens within rural chickens. Proceedings of XXII World's Poultry Congress, Istanbul, Turkey

Momoh, O.M., Ehiobu, N.O., Nwosu, C.C. 2007. Egg production of two Nigerian local chicken ecotypes under improved management. Proceedings of the 32nd Annual Conference of Nigerian Society for Animal Production, 18-21 March, 2007. University of Calabar 278-281.

Mtileni, B.J., Muchadeyi, F.C., Maiwashe, A., Groeneveld, E., Groeneveld, L.F., Dzama, K., Weigend, S. 2011. Genetic diversity and conservation of South African indigenous chicken populations. Journal of Animal Breeding and Genetics 128:209 $-218$.

Omondi, S.O. 2018. Economic analysis of small scale poultry production in Kenyan medium-sized cities of Kisumu and Thika. Proceedings of the $10^{\text {th }}$ International Conference of Agricultural Economists, Vancouver. Pp 1-35.

Osman, S.A.M., Yonezawa, T., Nishibori, M. 2016. Origin and genetic diversity plete sequence of mitochondrial DNA Dloop region. Poultry Science 95:1248-1256.

Savolainen, P., Zhang, Y.P., Luo, J., Lundeberg, J., Leitner, T. 2002. Genetic evidence for an East Asian origin of domestic dogs. Science 298(5598): 1610-1613

Simonsen K.L., Churchill, G.A., Aquadro, C.F. 1995.Properties of statistical tests of neutrality for DNA polymorphism data. Genetics 141(1): 413-429.

Sonaiya, E.B., Olori, V.E. 1990. Family poultry production in south western Nigeria. Proceedings of International Workshop held in November 13-16, 1989 at Obafemi Awolowo University, Ile Ife Nigeria. Pp 243247.

Taberlet, P., Coissac, E., Pansu, J., Pompanon, F. 2011. Conservation genetics of cattle, sheep and goats. Cell Research Biology 334: 247-254.

Tamura, K., Stecher, G., Peterson, D., Filipski, A., Kumar, S. 2013. MEGA6: Molecular Evolutionary Genetics Analysis version 6.0. Molecular Biology Evolution 30: 27252729.

Teinlek, P., Siripattarapravat, K., Tirawattanawanich, C. 2018. Genetic diversity analysis of Thai indigenous chickens based on complete sequences of mitochondrial DNA D-loop region. Asian-Australasian Journal of Animal Science 31(6): 804-811.

Thompson, J.D., Higgins, D.G., Gibson, T.J. 1994. CLUSTAL W: Improving the sensitivity of progressive multiple sequence alignment through sequence weighing, position-specific gap penalties and weight matrix 
A PRELIMINARY COMPARISON OF MITOCHONDRIAL D-LOOP REGION...

choice. Nucleic Acids Research 22: 4673-4680. netics Research International 928420: 1-8.

Wani, C.E., Yousif, I.A., Ibrahim, M.E., Wolf, C., Reutsch, J., Hubner, P. 1999.

Musa, H.H. 2014. Molecular characteriza- PCR-RFLP analysis of mitochondrial DNA:

tion of Sudanese and Southern Sudanese a reliable method for species identification.

chicken breeds using mtDNA D-loop. Ge- Journal of Agricultural and Food Chemistry 47(4):

(Manuscript received: 3rd February, 2020; accepted: 4th June, 2020). 